Int. J. Electrochem. Sci., 14 (2019) 10270 - 10280

\title{
Excellent Electrochemical Performance of Multilayer Graphite Nanosheets as an Anode Material for Lithium-Ion Batteries
}

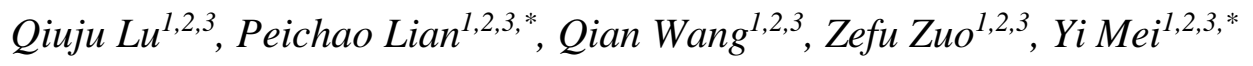 \\ ${ }^{1}$ Faculty of Chemical Engineering, Kunming University of Science and Technology, Kunming 650500, \\ China \\ ${ }^{2}$ Yunnan Provincial Key Laboratory of Energy Saving in Phosphorus Chemical Engineering and New \\ Phosphorus-based Materials \\ ${ }^{3}$ The Higher Educational Key Laboratory for Phosphorus Chemical Engineering of \\ Yunnan Province, Kunming 650500, China \\ *E-mail: lianpeichao@kmust.edu.cn; meiyi412@126.com
}

doi: $10.20964 / 2019.11 .28$

Received: 6 July 2019 / Accepted: 23 August 2019 / Published: 7 October 2019

\begin{abstract}
Graphite anodes occupy a considerable share of the commercial market of lithium-ion batteries (LIBs) due to their appropriate potential profile and low cost. Nevertheless, this type of anode material is far from enough to meet the increasing demands of electronic devices and hybrid electric vehicles (HEVs) due to its relatively low lithium storage capacity $\left(372 \mathrm{mAh} \mathrm{g}^{-1}\right.$ at $\left.\mathrm{LiC}_{6}\right)$. Graphene is a one-atom-thick layer of graphite that exhibits a larger reversible capacity than that of graphite but large voltage hysteresis and poor cycling performance during charge and discharge processes. Herein, multilayer graphite nanosheets (few-layer graphene) were prepared by using a facile and efficient high-pressure homogenizer method. The as-prepared multilayer graphite nanosheets were used as an anode material for LIBs and exhibited good cycling stability and rate performance. After 50 cycles, the material still retained a high reversible capacity of $573 \mathrm{mAh} \mathrm{g}^{-1}$ at a current density of $100 \mathrm{~mA} \mathrm{~g}^{-1}$. Even at a high current density of $1000 \mathrm{~mA} \mathrm{~g}^{-1}$, the reversible specific capacity of the prepared multilayer graphite nanosheets is still as high as $510 \mathrm{mAh} \mathrm{g}^{-1}$. More importantly, the multilayer graphite nanosheets have no obvious voltage hysteresis.
\end{abstract}

Keywords: Multilayer graphite nanosheets; High-pressure homogenizer method; Anode materials; Lithium-ion batteries

\section{$\underline{\text { FULL TEXT }}$}

(C) 2019 The Authors. Published by ESG (www.electrochemsci.org). This article is an open access article distributed under the terms and conditions of the Creative Commons Attribution license (http://creativecommons.org/licenses/by/4.0/). 